\title{
AFIKS-AFIKS PEMBENTUK VERBA DENOMINAL DALAM BAHASA JAWA
}

\author{
Nanik Herawati ${ }^{1}$; Rustono $^{2}$; Soepomo Poedjosoedarmo $^{3}$ \\ ${ }^{1}$ Mahasiswa S3 Linguistik Universitas Sebelas Maret Surakarta \\ ${ }^{2}$ Universitas Negeri Semarang \\ ${ }^{3}$ Universitas Gadjah Mada Yogyakarta \\ 1'magistraunwidha@yahoo.com
}

\begin{abstract}
Research purposes are (1) to identify affixes in Javanese language which form denominal verbs and to explain the functions and meanings of javanese verbal derivation, and (2) to explain productivity of derivative affixes in forming denominal verbs in Javanese languange. The theoritical basis used in the research covers (1) morphology, (2) verbs, (3) affixes, (4) derivational morphology, (5) inflectional morphology (6) kinds of Javanese derivations, and (7) productivity of affixes in Javanese verbs. This research is qualitative one with linguistic structure as research method. This research data is in the form of sentences in which there are verb affixation that occupy the function as predikat in the sentences. Agih method is used in data analysis. The study of denominal verb in the Javanese language with the process of affixation can be in the forms of: (1) affixes that form denominal verbs, (2) infixes that form denominal verbs, (3) suffixes that form denominal verb, and (4) combined affixed that form denominal verbs. Productivity of affixes in forming Javanese denominal verbs can be: (1) prefix with high productivity in forming Javanese denominal verbs, (2) infixes with fair productivity in forming Javanese denominal verbs, (3) suffixes with high productivity in forming Javanese denominal verbs, and (4) combined affixes with high productivity in forming Javanese denominal verbs.
\end{abstract}

Key words: derivation, affixes, verbs.

\section{PENDAHULUAN}

Infleksi dan derivasi merupakan persoalan klasik di dalam tata bahasa tradisional dan selalu dibedakan di dalam pemerian morfologi bahasa Indo-Eropa (Subroto:53). Meskipun keduanya merupakan proses morfologi yang berbeda, keduanya saling berkaitan erat antara satu dengan yang lain dan pemerian tentang keduanya saling melengkapi.

Menurut Subroto (1985) proses derivasional ada dua macam, yakni derivasi transposisional dan derivasi taktransposisional. Derivasi transposisional adalah derivasi yang mengakibatkan terjadinya perubahan kelas kata, sedangkan derivasi taktransposisional adalah derivasi yang tidak mengubah kelas katanya. 
Ada banyak pakar bahasa yang membicarakan derivasi dan infleksi antara lain: Uhlenbeck (1953, 1971), Lyons (1968), Matthews (1974), Subroto (1985), Bauer (1988), Katamba (1993), Verhaar (1999). Artikel Uhlenbeck (1983) berfokus pada masalah morfologi verba. Lyons (1968) membicarakan masalah morfologi derivasi dan morfologi infleksi, begitu juga Matthews (1974) memilah morfologi menjadi dua yakni morfologi inflkesional dan morfologi derivasional. Subroto (1985) dalam disertasinya yang berjudul Transposisi dari Adjektiva menjadi Verba dan Sebaliknya. Bauer (1983) juga memilah morfologi menjadi dua bentuk infleksi dan word formation (membicarakan tentang afiksasi derivasional dan pemajemukan).

Penelitian ini hanya difokuskan pada afiks-afiks pembentuk verba denominal dalam bahasa Jawa. Verba denominal maksudnya kata kerja yang berasal dari bentuk dasar kata benda. Proses derivasi dalam bahasa Jawa dibedakan menjadi dua yakni derivasi transposisional dan derivasi taktransposisional. Verba denominal, merupakan proses derivasi yang transposisional. Berdasarkan latar belakang masalah tersebut, maka dapat dirumuskan beberapa permasalahan, sebagai berikut: 1) Afiks-afiks apa saja yang membentuk verba denominal dalam bahasa Jawa? 2) Bagaimanakah produktivitas afiks-afiks dalam menurunkan verba denominal bahasa Jawa? Tujuan penelitian ini adalah 1) Mengidentifikasikan afiks-afiks Bahasa Jawa yang membentuk verba denominal serta menjelaskan fungsi dan makna derivasi dalam menurunkan verba bahasa Jawa. 2) Memaparkan produktivitas afiks derivasi dalam menurunkan verba denominal.

\section{TEORI DAN METODOLOGI}

\section{Disertasi Subroto (1985)}

Disertasi Subroto (1985) yang berjudul "Transposisi dari Adjektiva Menjadi Verba dan Sebaliknya dalam Bahasa Jawa" membedakan derivasi dan infleksi. Selain itu juga menyebut proses derivasi tersebut dengan istilah transposisi bila berubah kelas katanya dan taktransposisi bila tidak berubah kelas katanya. 


\section{Morfologi}

Menurut Kridalaksana (1982:111) morfologi merupakan bidang linguistik yang mempelajari morfem dan kombinasi-kombinasinya : Kajian morfologi disini mencakup satuan-satuan terkecil yaitu morfem dan satuan terbesar yaitu kata. Morfologi mempelajari seluk beluk pembentukan kata disertai dengan perubahan fungsi dari makna.

Sulchair (1987:50) mengatakan proses morfologi ada tiga macam, yaitu afiksasi, reduplikasi, dan pemajemukan. Perubahan kata dengan afiksasi seperti pada kata kathok 'celana' $(\mathrm{N}) \rightarrow$ kathokan 'memakai celana' (V), paku 'paku' $(\mathrm{N}) \rightarrow$ maku 'memaku' (V).

\section{Verba}

Bahasa Indonesia dan Bahasa Jawa mengenal dua macam bentuk verba, yaitu (1) verba asal dan (2) verba turunan. Verba asal dapat berdiri sendiri tanpa afiks dalam konteks sintaksis, seperti adus, turu, lunga, mati. Verba turunan verba yang menggunakan afiks, dibedakan menjadi tiga kelompok, yaitu; a. Verba yang dasarnya adalah dasar bebas misalnya singkir 'singkir', memerlukan afiks agar dapat berfungsi sebagai verba sehingga menjadi nyingkir 'menepi'; b. Verba yang dasarnya adalah dasar bebas misalnya lunga 'pergi' yang dapat berdiri sendiri sekaligus dapat pula memiliki afiks misalnya nglungani 'pergi diam-diam'; c. Verba yang dasarnya adalah dasar terikat misalnya tети 'temu' yang memerlukan afiks sehingga menjadi пети.

\section{Afiksasi}

Salah satu proses morfologis yang ada pada bahasa Jawa ialah proses afiksasi.

a. Prefiks (Ater-ater) : Prefiks atau ater-ater merupakan imbuhan yang ditempatkan di awal kata. Prefiks bahasa Jawa berupa ater-ater anuswara $\{m-, n-, n g-$, dan $n y-\}$ ater-ater $\{a-\},\{$ ma N-\}, \{ka-\}, \{ke-\}, \{di-\}, \{sa-\}, \{mi-\}, \{pa-\}, \{mer-\}, pa+anuswara 


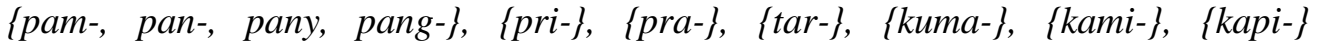

(Wedhawati, 2006).

b. Infiks (seselan) : Infiks atau seselan adalah imbuhan yang dilekatkan ditengah kata atau diawal kata, berupa : $\{$-um- $\},\{$-in $\},\{$-el- $\},\{$-er $\}$. Penggunaan infiks seperti : tinali, ginandheng

c. Sufiks (Panambang) : Sufiks atau panambang merupakan imbuhan yang dilekatkan di akhir kata dasar. Sufiks bahasa Jawa yaitu : $\{-a\},\{e\}$ beralomorf $\{-n e,-i p u n\},\{-i\}$ beralomorf $\{-n i\},\{-a n\}$ beralomorf $\{-n a n\},\{-e r\},\{-a n e\},\{-a n a\},\{-a k e\}$ beralomorf $\{-$ ke dan aken\}, \{-ne\}, dan \{-na\}. Penggunaan sufiks seperti tukua, bungkuse

d. Konfiks (ater-ater + panambang) : Konfiks adalah gabungan prefiks dan sufiks pada kata dasar. Gabungan antar ater-ater dan panambang yaitu : $\{\mathrm{N}+-\mathrm{a},-\mathrm{na},-\mathrm{i},-\mathrm{e}$, ake $\},\{$ di+ -e, a, i, ne, ake $\},\{$ pa $+-a n$, ane $\}$. Contoh konfiks di dalam bahasa Jawa : padusan, nulisake

\section{Morfologi Derivasional dan Infleksional}

Pembahasan mengenai derivasi oleh Bauer (1988:75-84) yakni: (1) derivasi mengakibatkan perubahan kategori kelas kata, (2) afiks infleksi mempunyai makna tetap, (3) derivasi kurang produktif bila dibandingkan infleksi, (4) afiks derivatif lebih dekat ke akar bila dibandingkan infleksi, (5) hasil derivasi dapat digantikan oleh bentuk monomorfemik, (6) infleksi merupakan afiks yang tertutup, morfologi infleksi relevan untuk sintaksis.

\section{Produktivitas Afiksasi pada Verba Bahasa Jawa}

Bauer (1983: 63) menyatakan bahwa produktivitas adalah salah satu perlengkapan bahasa yang memungkinkan pembicara asli bahasa itu dalam menghasilkan bentukan-bentukan yang takterbatas jumlahnya dan beberapa di antaranya merupakan bentukan baru. 


\section{Metodologi Penelitian}

Penelitian ini termasuk penelitian kualitatif. Penelitian kualitatif merupakan penelitian yang bersifat deskriptif, dengan cara menganalisis data secara induktif (Subroto 1992:7) penelitian kualitatif dipandang tepat untuk mengkaji masalah morfologi afiksasi verba Bahasa Jawa. Metode yang digunakan adalah metode deskriptif, dalam arti memerikan gejala-gejala lingual secara cermat dan teliti. Jenis penelitian deskriptif kualitatif dengan setting apa adanya yang pada dasarnya mendeskripsikan secara kualitatif dalam bentuk kata-kata, bukan angkaangka matematis atau statistik (Lindlof, 1994: 21).

Metode yang digunakan untuk menganalisis data adalah metode Agih (Sudaryanto, 1993: 15) yang alat penentunya adalah bahasa itu sendiri. Teknik analisis data menggunakan analisis interaktif (Sutopo, 200). Adapun siklus pengumpulan data bersifat induktif yang mencakup seleksi data, klasifikasi data, dan penyajian data.

Untuk menemukan kaidah dalam tahap analisis data menggunakan metode padan, metode agih, dan metode reflektif introspeksi (Sudaryanto, 2001). Untuk menganalisis proses afiksasi derivative digunakan teknik oposisi dua-dua. Teknik oposisi dua-dua adalah teknik mengoposisikan verba afiksasi atau reduplikasi dengan D (Subroto, 1992:72). Teknik oposisi dua-dua bertujuan untuk menunjukkan ada tidaknya perbedaan identitas leksikal yang menyangkut perbedaan kelas kata.

\section{AFIKS-AFIKS PEMBENTUK VERBA DENOMINAL, FUNGSI DAN MAKNA DALAM MENURUNKAN BAHASA JAWA}

\section{A. Prefiks Pembentuk Verba Denominal}

\section{Prefiks Nasal $\{N-\}$}

Bentuk Prefiks Nasal $\{\mathrm{N}-\}$ atau suara hidung mempunyai lima alomorf yaitu, $\{\mathrm{m}-$, $\mathrm{N}-$, ng-, ny-, dan nge $\}$. Verba bentuk $\{\mathrm{N}-\}$ termasuk verba aktif transitif atau intransitif. Apabila $\{\mathrm{N}-\}$ diikuti oleh morfem dasar berawal dengan fonem $/ \mathrm{p} /, / \mathrm{w} /, / \mathrm{m} /, / \mathrm{t} /, / \mathrm{th} /, / \mathrm{n} /$, /k/, /s/, /c/, dan /ny/ maka akan luluh menjadi satu dengan $\{\mathrm{N}-\}$. Prefiks $\{\mathrm{N}-\}$ akan 
berbentuk /m-/ apabila morfem dasar berawal dengan konsonan /b, p, dan w/. Contoh: mbanyu, pacul, madung

Fungsi Prefiks $\{\mathrm{N}-\}$ adalah pembentuk verba aktif. Contoh kata kerja aktif transposisi dari kata benda dengan prefiks $\{\mathrm{N}-\}$ yaitu: nggunting, nyendhok, nyethok, nguping.

Makna Prefiks Nasal $\{\mathrm{N}-\}$

a. $\mathrm{D}+\{\mathrm{N}-\}$ 'melakukan perbuatan atau aktivitas sesuai dengan apa yang dinyatakan pada bentuk dasar.

(1) Bapak macul neng kebon. macul 'melakukan aktivitas mencangkul'

(2) Mas Danu lagi latihan mbedhil. mbedhil 'melakukan aktivitas menembak'

Perubahan kelas kata dari nomina menjadi verba tersebut dapat diketahui dengan tes keanggotaan kategorial dan juga dapat dilakukan pengecekan dengan teknik oposisi dua-dua sebagai berikut.

\begin{tabular}{|l|l|l|l|}
\hline No. & Verba Denominal & Bentuk Dasar & Proses Afiksasi \\
\hline 1. & macul $(\mathrm{V})$ & $\operatorname{pacul}(\mathrm{N})$ & $\{\mathrm{N}-\}+$ D \\
\hline 2. & mbedhil $(\mathrm{V})$ & bedhil $(\mathrm{N})$ & $\{\mathrm{N}-\}+\mathrm{D}$ \\
\hline
\end{tabular}

\section{B. Infiks Pembentuk Verba Denominal}

Infiks atau seselan yaitu imbuhan yang dilekatkan di tengah kata atau di awal kata.

Afiks dalam bahasa Jawa ada empat yaitu: $\{-$ um- $\},\{-$ in- $\},\{$ el- $\}$. dan $-\{$ er- $\}$.

\section{Infiks $\{$-in $\}$}

Bentuk verba infiks $\{$-in- $\}$ termasuk verba pasif. Verba bentuk $\{$-in- $\}$ dipergunakan jika pelaku tindakan orang ketiga, baik tunggal maupun jamak.

Fungsi Infiks $\{$-in $\}$ : pembentuk verba pasif. Contoh kata kerja pasif transposisi dari kata benda : inguleg, tinali.

Makna Infiks $\{-$ in- $\}$

a. $\mathrm{D}+\{$-in- $\}$ 'dikenai tindakan seperti yang dilakukan pada bentuk dasarnya'

(3) Sambele inguleg nganti lembut. inguleg 'diuleg' 
(4) Bukune Dewi tinali pita. tinali'ditali

Perubahan kelas kata dari nomina menjadi verba di atas dapat diketahui dengan tes keanggotaan kategorial dan juga dapat dilakukan pengecekan dengan teknik oposisi dua-dua, sebagai berikut.

\begin{tabular}{|l|l|l|l|}
\hline No. & Verba Denominal & Bentuk Dasar & Proses Afiksasi \\
\hline 1. & inguleg $(\mathrm{V})$ & uleg $(\mathrm{N})$ & $\{-\mathrm{in}-\}+\mathrm{D}$ \\
\hline 2. & tinali $(\mathrm{V})$ & tali $(\mathrm{N})$ & $\{-\mathrm{in}-\}+\mathrm{D}$ \\
\hline
\end{tabular}

\section{Sufiks Pembentuk Verba Denominal}

Sufiks bisa juga disebut panambang atau bahkan ada yang menyebut akhiran. Sufiks yaitu imbuhanyang dilekatkan di akhir kata.

\section{Sufik $\{-\mathbf{a}\}$}

Bentuk Sufik $\{-\mathbf{a}\}$ : Sufiks $\{-\mathrm{a}\}$ bisa bersambung dengan kata yang berakhir vokal maupun konsonan. Sufiks $\{-a\}$ termasuk verba inperatif.

Fungsi Sufik $\{-\mathbf{a}\}$ :Pembentuk verba imperatif, pengandaian, dan pegharapan. Kata kerja imperatif dipergunakan untukmemberikan perintah pada orang kedua.

Makna verba $\{-\mathrm{a}\}$ sebagai berikut.

a. $\mathrm{D}+\{-\mathrm{a}\}$ 'perintah untuk bertindak pada orang kedua'

(5) Bud, omaha neng ndesa wae!, omaha 'berumahlah'

(6) Jamua sik, ben awakmu sehat!, jamua 'minumlah jamu'

Perubahan kelas kata dari nomina menjadi verba di atas dapat diketahui dengan tes keanggotaan kategorial dan juga dapat dilakukan pengecekan dengan teknik oposisi dua-dua sebagai berikut.

\begin{tabular}{|l|l|l|l|}
\hline No. & Verba Denominal & Bentuk Dasar & Proses Afiksasi \\
\hline 1. & отаһ $a(\mathrm{~V})$ & отаһ $(\mathrm{N})$ & $\mathrm{D}+\{-\mathrm{a}\}$ \\
\hline 2. & јати $(\mathrm{V})$ & јати $(\mathrm{N})$ & $\mathrm{D}+\{-\mathrm{a}\}$ \\
\hline
\end{tabular}

\section{Konfiks Pembentuk Verba Denominal}

1. Konfiks $\{\mathrm{N}-\ldots-\mathrm{i}\}$ 
Bentuk Konfiks $\{\mathrm{N}-\ldots-\mathrm{i}\}$ : konfiks $\{\mathrm{N}-\ldots-\mathrm{i}\}$ apabila melekat pada bentuk dasar nomina akan menjadi verba aktif. Contoh konfiks $\{\mathrm{N}-\ldots-\mathrm{i}\}$ makoni, ngguntingi, nyamaki.

Fungsi Konfiks $\{\mathrm{N}-\ldots-\mathrm{i}\}$ : konfiks $\{\mathrm{N}-\ldots-\mathrm{i}\}$ merupakan pembentuk verba aktif transitif. Contoh konfiks $\{\mathrm{N}-\ldots-\mathrm{i}\}$ verba aktif transitif: ngunyahi, naleni.

Makna Konfiks $\{\mathrm{N}-\ldots-\mathrm{i}\}$

1) $\mathrm{D}+\{\mathrm{N}-\ldots-\mathrm{i}\}$ 'memberi seperti apa yang dinyatakan pada bentuk dasarnya'

(7) Menehi dheweki kuwi kaya nguyahi segara. nguyahi 'memberi garam'

(8) Bu Warnu naleni klambine, ben kenceng. naleni'memberi tali'

Perubahan kelas kata dari nomina menjadi verba di atas dapat diketahui dengan tes keanggotaan kategorial dan juga dapat dilakukan pengecekan dengan teknik oposisi duadua, sebagai berikut.

\begin{tabular}{|l|l|l|l|}
\hline No. & Verba Denominal & Bentuk Dasar & Proses Afiksasi \\
\hline 1. & nguyahi $(\mathrm{V})$ & uyah $(\mathrm{N})$ & $\mathrm{D}+\{\mathrm{N}-\ldots-\mathrm{i}\}$ \\
\hline 2. & naleni $(\mathrm{V})$ & tali $(\mathrm{N})$ & $\mathrm{D}+\{\mathrm{N}-\ldots-\mathrm{i}\}$ \\
\hline
\end{tabular}

\section{PRODUKTIVITAS AFIKS-AFIKS PEMBENTUK VERBA DENOMINAL DALAM} MENURUNKAN BAHASA JAWA

\section{A. Produktivitas Prefiks Nasal $\{\mathbf{N}-\}$}

Produktivitas berkaitan dengan fenomena yang nyata dari pembentukan kata dengan proses afiksasi. Produktivitas di sini berarti pembentukkan kata dengan prefiks nasal $\{\mathrm{N}-\}$ di dalam penerapan pola atau kaidah produktif, diterapkan secara terus menerus, bersifat terbuka dalam sistem tersebut berkaitan dengan jumlah yang banyak atau besar. Ada beberapa tingkatan yang berhubungan dengan masalah Produktivitas pembentukan kata, yaitu: produktif, cukup produktif, kurang produktif, tidak produktif.

Dilihat dari kriteria di atas, prefiks Nasal $\{\mathrm{N}-\}$ di dalam proses pembentukan kata derivasional sangat produktif dan kaidahnya sangat sistematik, pola atau kaidah pembentukan verba denominal bisa diterapkan terus menerus, sifatnya terbuka dalam sistem itu, mencakup jumlah yang banyak. 


\section{B. Produktivitas Infiks $\{$-in- $\}$}

Infiks $\{$-in- $\}$ dalam pembentukan verba denomina cukup produktif. Pola dan kaidahnya sitematik, bisa menjadi infiks bagi bebrerapa bentuk dasar yang memenuhi syarat, cukup bisa diterapkan terus menerus dan sifatnya cukup terbuka dalam sistem itu, jumlahnya cukup banyak

C. Produktivitas Sufiks $\{-\mathbf{a}\}$

Sufiks $\{-\mathrm{a}\}$ dalam pembentukan verba denomina kurang produktif. Pola atau kaidah pembentulan verba denominal dengan proses sufiks $\{-\mathrm{a}\}$ kurang bisa diterapkan terus menerus dan sifatnya kurang terbuka dalam sistem itu, mencakup jumlah yang kurang banyak.

\section{Produktivitas Konfiks $\{\mathrm{N}-\ldots-. \mathrm{-i} /-\mathrm{ni}\}$}

Konfiks $\{\mathrm{N}-. . .-\mathrm{i} /-\mathrm{ni}\}$ dalam pembentkan verba denomina produktif. Pola atau kaidah pembentulan Verba denominal dengan proses konfiks $\{\mathrm{N}-\ldots-\mathrm{i} /-\mathrm{ni}\}$ bisa diterapkan terus menerus dan sifatnya terbuka dalam sistem itu, mencakup jumlah yang banyak, dan sistematik.

\section{SIMPULAN}

Penelitian ini hanya membahas tentang afiks-afiks pembentuk verba denominal dalam bahasa Jawa.

\section{Prefiks Pembentuk Verba Denominal.}

Prefiks $\{\mathrm{N}-\}+$ D, Fungsi : membentuk verba aktif, adapun maknanya sebagai berikut: 'melakukan perbuatan atau aktifitas sesuai dengan apa yang dinyatakan pada bentuk dasar.

\section{Infiks Pembentuk Verba Denominal}

Infiks $\{$-in $\}$ termasuk verba pasif, dipergunakan jika pelaku tindakan orang ketiga, baik tunggal maupun jamak.

\section{Sufiks Pembentuk Verba Denominal}


Sufik $\{-\mathrm{a}\}$ bisa bersambung dengan kata yang berakhir vokal maupun konsonan. Beberapa bentuk Verba denominal dengan proses sufiks $\{-\mathrm{a}\}$ misalkan udana, grimisa, mendunga. Fungsi verba $\{-\mathrm{a}\}$ Pembentuk verba imperatif, pengandaian, dan pegharapan. Makna verba $\{$-a $\}$ sebagai 'perintah untuk bertindak pada orang kedua'.

\section{Konfiks Pembentuk Verba Denominal}

Konfiks $\{\mathrm{N}-\mathrm{-i}\}$ apabila melekat pada bentuk dasar nomina akan menjadi kata kerja atau verba denominal, seperti kata paku, gunting, samak bila mendapat imbuhan konfiks [N- -i] menjadi makoni, ngguntingi, nyamaki. Fungsi: Verba denomina bentuk [N- -i] termasuk verba aktif transitif dengan bentuk dasar yang berwujud morfem pangkal. Makna: memberi seperti apa yang dinyatakan pada bentuk dasarnya; memakaikan seperti apa yang dinyatakan pada bentuk dasarnya.

\section{DAFTAR PUSTAKA}

Bauer, Laurie. 1983 . English word-Formation. Cambridge: Cambridge University Press

Bauer, Laurie. 1988. Introducing Linguistic Morphology. Great Britain: Edinburgh University Press.

Chaer, Abdul. 2003. Seputar Tatabahasa Baku Bahasa Indonesia. Jakarta: Rineka Cipta.

Eko Wardono, B. Karno. 1982. "Verba Denomina dan Nomina Deverba dalam Bahasa Jawa Baku”. Disertasi, Jakarta: Universitas Indonesia.

Katamba, Francis. 1994. Morphology. London: The Macmillan Press.

Kridalaksana, Harimurti. 1985. Tata Bahasa Deskriptif Bahasa Indonesia. Jakarta: Pusat Pembinaan dan Pengembangan Bahasa.

Kridalaksana, Harimurti. 1988. Pembentukan Kata dalam Bahasa Indonesia. Jakarta: Gramedia Pustaka Utama.

Lyons, John. 1995. Pengantar Teori Linguistik. (Terjemahan I. Soetikno) . Jakarta: Gramedia.

Leech, Geoffrey. 1997. Semantik ( Terjemahan Paina dan Soemitro). Surakarta: Sebelas Maret University Press.

Matthews, P.H. 1974. Morphology: An Introduction to the Theory of World-Structure. Cammbridge: Cambridge University Press.

M. Ramlan. 1985. Morfologi: Suatu Tinjauan Deskriptif. Yogyakarta; C.V. Karyono. 
Padmasoekatja, S. 1986. Paramasastra Jawa. Surabaya: Citra Jaya Murti.

Parera, Jos Daniel. 1994. Morfologi Bahasa. Jakarta: Gramedia.

Poedjosoedarmo, Soepomo dkk, 1979. Kajian Morfologi Bahasa Jawa. Jakarta: Pusat Pembinaan dan Pengembangan Bahasa.

Purnanto, Dwi. 2006. "Kajian Morfologi Derivasional dan Infleksional dalam Bahasa Indonesia”. Jurnal Kajian Linguistik dan Sastra.

Sasangka, Sry Satriya Tjatur Wisnu. 2001. Paramasastra Jawa Gagrag Anyar. Jakarta: Yayasan Paramalingua

Soetopo, H.B. 1996. Metodologi Penelitian Kualitatif: Metodologi Penelitian untuk Ilmu- Ilmu Sosial dan Budaya. Surakarta: Universitas Sebelas Maret Surakarta.

Subroto, D. Edi. 1985. 'Transposisi dari Adjektiva Menjadi Verba dan sebaliknya dalam Bahasa Jawa'. Desertasi Universitas Indonesia.

Subroto, D. Edi. 1985. "Infleksi dan Derivasi (Kemungkinan Penerapannya dalam Pemerian Morfologi Bahasa Indonesia)", Makalah dalam Pertemuan Ilmiah VII Bahasa dan Sastra Indonesia, se-Jateng dan DIY, 14-15 Oktober 1985. Yogyakarta: Sarjana Wiyata Taman Siswa.

Sudaryanto, 2001. Metode dan Analisis Bahasa Pengantar Penelitian Wahana Kebudayaan secara Linguistik. Yogyakarta: Duta Wacana Universitas Press.

Tampubolon. 1983. Verbal Affixition in Indonesian: A semantic Exploration. Australia: The Australian National University.

Uhlenbeck, E.M. 1982. Kajian Morfologi Bahasa Jawa. Jakarta: Djambatan.

Verhaar, J.W.M. 1977. Pengantar Linguistik. Yogyakarta: Gajahmada University Press.

Verhaar, J.W.M, 2001. Asas-Asas linguistik Umum. Yogyakarta: Gajahmada University Press.

Wedhawati. 2001. Tata Bahasa Jawa Mutakhir. Jakarta: Pusat Pembinaan dan pengembangan Bahasa. 